\section{Value Pricing}

\section{David J. Eaglesham}

The cynic, according to Oscar Wilde, knows the price of everything and the value of nothing. I realized recently that the materials scientist, in contrast, knows the value of everything and the price of nothing.

A brief swing through a Materials Research Society meeting will quickly convince you that materials scientists are very good at identifying all the ways in which things are valuable. We engineer materials combinations and tweak processes to achieve specific attributes with great precision. We are familiar in gory detail with the performance of the existing materials in our field. We can reel off conductivities, diffusivities, viscosities, porosities, elasticities, anisotropies, specific gravities. Hardnesses, stiffnesses, toughnesses, roughnesses. Bandgaps, lattice constants, effective masses, refractive indices. But in general we are unable to come even close to a measure of the price of the materials, even though price is likely to be more important than any other attribute in the materialsselection for commercial application.

Any real materials-selection exercise will typically, and quickly, come down to a cost-performance trade-off. The materials scientist can usually just do the performance-performance trade-off. Why use copper when the resistivity of gold is almost as low? (as we used to say at Bell Labs). Even if we do not always know the answer, performance information is extremely easy to "Google." Almost any property is tabulated for most relevant materials within about two clicks of the home page. More complex questions of materials integration can take longer to establish (and a lifetime to figure out), but the relevant literature can at least be found in minutes. Cost information, how-

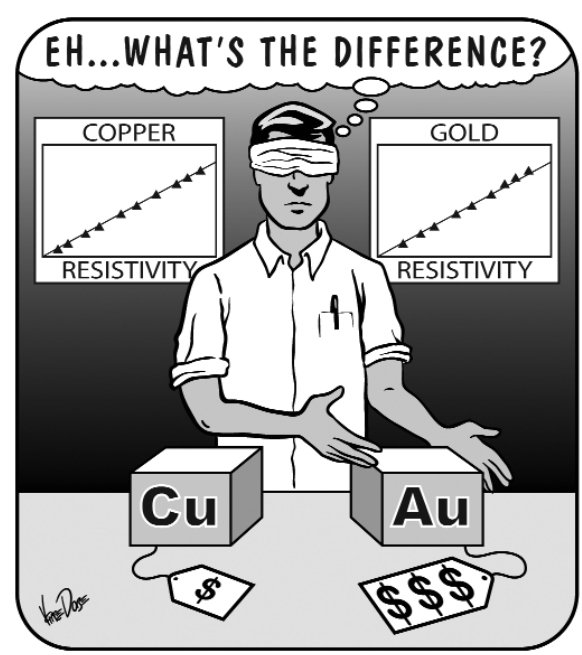

ever? That is hard to come by. So, naturally, we tend to ignore it.

An informal survey of MRS members that I conducted showed how widespread is this approach. Prominent experts in polymers told me they had no idea of the relative cost of everyday polymers. Worldfamous metallurgists professed complete ignorance of the cost-difference between stainless and mild steel. Semiconductor physicists, asked for the relative cost-per$\mathrm{cm}^{2}$ of $\mathrm{Si}$ and $\mathrm{GaAs}$, responded, "150 meV? No, no, it's $15 \mathrm{~cm}^{2} /$ Vs. Erm, $5 \mathrm{Ohm} / \mathrm{sq}$ ?"

Perhaps more significantly, most people were baffled to be asked. Why would it matter? It is a negligible component of research and development costs for the majority of researchers, after all. Ask a

Material Matters is a forum for expressing personal points of view on issues of interest to the materials community. similar cross-section of the MRS membership for the current price of textbooks or laboratory consumables and a hard number will come back, fast. Most people seem to be able to give rough dollars for all their direct budget items (e.g., commercial secondary-ion mass spectrometry analysis), and estimate many indirect ones (e.g., an hour's-worth of smallangle-neutron scattering). These are numbers we live by. But the day-to-day existence of a materials researcher is touched little, if at all, by the crude cost of the materials themselves.

But is this not alarming in itself? Out in the cold, hard world beyond the confines of Copley Square and the Moscone Center, cost is the primary driver for materials adoption. How can materials scientists influence materials adoption if this core attribute is not on our radar?

Now there are reasons why "hard" scientists like to stay away from cost information. It is often closely held, and it changes very dynamically. It also depends heavily on "soft" attributes (e.g., manufacturing volume and competitive position) that are not scientific. But given its central importance in real-world applications, we owe it to our field to treat materials cost with the respect it deserves.

As a partial solution, I would suggest that we aim to incorporate basic cost information into materials education. I also offer the following proposal, which I think would be instructive for the field. As a line item in all proposals for research, funding agencies supporting basic materials research could require a line item for $1 \mathrm{~kg}$ of the actual material being studied. This would provide a baseline for the researchers, but would also provide the referees with an opportunity to assess the likelihood of the discussed applications. An exception could be made for bionano proposals using materials such as engineered proteins and sub-nm clusters. These, I would suggest, should be required to budget $10 \mathrm{~kg}$.

David J. Eaglesham is Vice President of Technology at First Solar, Perrysburg, Ohio.

\begin{tabular}{l|l|l} 
ACNS2008 & $\begin{array}{l}\text { 4TH AMERICAN CONFERENCE ON NEUTRON SCATTERING } \\
\text { May 11-15 • } 2008\end{array}$ \\
\hline
\end{tabular}

